\title{
Remote Home Security System using Open-Source Electronic Platform
}

\author{
Rachell V. De Guzman \\ San Carlos College \\ Bonifacio, San Carlos City \\ Pangasinan, Philippines
}

\author{
Clarissa Joy M. Lubrido \\ San Carlos College \\ Bolingit, San Carlos City \\ Pangasinan, Philippines
}

\author{
Claire N. Reyes \\ San Carlos College \\ Agdao, San Carlos City \\ Pangasinan, Philippines
}

\begin{abstract}
These days, there are a lot of incidents of home robbery done either through "akyat-bahay" and / or inside job. Theft has increased a lot in today's world and not everyone can afford costly security system. This study proposes construction of a Remote Home Security System Using Open-Source Electronic Platform. The system is fully digital and also be fully customized. If the burglar detected the system would automatically notify the user that there is someone entered to the house and the siren will activated and rang until the user turn off using SMS or Bluetooth connection. This project aim to prevent the crimes inside the house.
\end{abstract}

\section{Keywords}

Arduino, GSM, home automation, home security, microcontroller, Open-source Electronic Platform, Security alarm.

\section{INTRODUCTION}

Security systems play an important role in the protection of lives. The purpose of home alarm system is to alert the homeowners of unauthorized entry attempts into the area. Others enter through ground floor windows or the back door of the house because it is more secluded and with minimal lighting than the front door entrance. ${ }^{1}$ With the development of new electronic technologies and their integration with older, traditional building technologies, smart house is fast becoming a reality. This is achieved by the incorporation of numerous subsystems into the security system with a single control unit such as surveillance, burglar control, access control, etc. An internet and Bluetooth based home security system focus on controlling and monitoring home security devices whether you are inside or outside your house.

The inability to access and control the security from remote location is one of the major reasons for lack of security against burglars and untoward incidents like fire and discomfort in leaving the house. These problems often lead to the loss of material things, properties and even loss of lives. These problems and other subsequent problems can be stopped if technologies will be utilized to better manage security devices. One way to do this is with the use of an open-source electronic platforms such as Arduino.

${ }^{2}$ Arduino is a single-board microcontroller that utilizes electronics in multidisciplinary and makes projects more accessible. Arduino boards are able to read inputs, like light sensors, activating a motor and turning on a LED light, etc. A microcontroller is a small computer on a single integrated circuit containing a processor core, memory, and programmable input/output peripherals.

With the above-mentioned problems and technologies, the proponents propose a remote home security system using an open-source electronic platform. This includes the manual siren alarm, security and alarm system which includes basic motion-sensing alarm that detects when someone enters the area. When an intruder is detected, it activates a siren and notify the authorized person via SMS (Short Message Service).

\section{RELATED LITERATURE}

These days, there are a lot of incidents of home robbery done either through "akyat-bahay" and / or inside job. ${ }^{3}$ In March 16, 2018 a series of robberies were committed on several houses and condominiums in the city and some towns in Cavite totaling 2 million pesos worth of money and expensive jewelries, gadgets and appliances. From the occurrence of that event, no action has been done to solve the problem due to lack of evidences. More often than not, these robberies causes tragedy such as loss of lives. ${ }^{4}$ This happens because homeowners would not easily give in without having a fight. Similar incident happens in Caloocan City, Philippines last December 2016 where a robbery turns into a shooting incident. ${ }^{5,6}$ Aside from houses, a grocery store was robbed by a 50-year old man in Sampalok, Manila in February 2018. These are just three examples of tragedies that have occurred in the recent years. To avoid these situations the proponents have taken a project that will help avoid these crimes. This can be done with the use of an open-source electronic platform such as Arduino. Over the years Arduino has been the brain of thousands of projects, from everyday objects to complex scientific instruments.

This system helps to protect the home especially entry point of the house from burglars and crooks. At the current situation, all the industries, banks or organizations use the security system to protect their premises from burglars. ${ }^{7}$ The "Home Automation and Security using Arduino Microcontroller " was the proposed study presented by Viraj Mali, Ankit Gorizia, Meghana Patil, Prof. P.S. Wawage in 2016 in International Journal of Research in Advent Technology (E-ISSN: 2321-9637) Special Issue. The system uses the Arduino microcontroller which is used to interface the Bluetooth and Wi-Fi shield of the Arduino to make it possible for the microcontroller to provide both technology as media for communication and control using Wi-Fi to remotely monitor the system. ${ }^{8}$ The DEVCON Home Security published a thorough introduction of home security system. The system is equipped with sensors and motion detectors. When an uninvited visitor arrives at home and tampers with door knobs, windows, or garage door, the sensors will trigger an alarm. Some systems include an outdoor and indoor siren that will alert the homeowner and neighbors of an intruder.

M. Sathishkumar, S.Rajini ${ }^{11}$ proposed a study entitled "Smart Surveillance System Using PIR sensor Network and GSM". This system is implemented using PIC microcontroller, 
camera, GSM and sensors. Nowadays, most of them are using wireless security system. It is easy to use and can be easily controlled by the homeowners. The wireless system securities are camera, motion sensor detector and alarm sound. With the help of this systems, the home is secured. The home security systems are frequently used to monitor detector and motion sensor.

\section{PROJECT DESIGN AND METHODOLOGY}

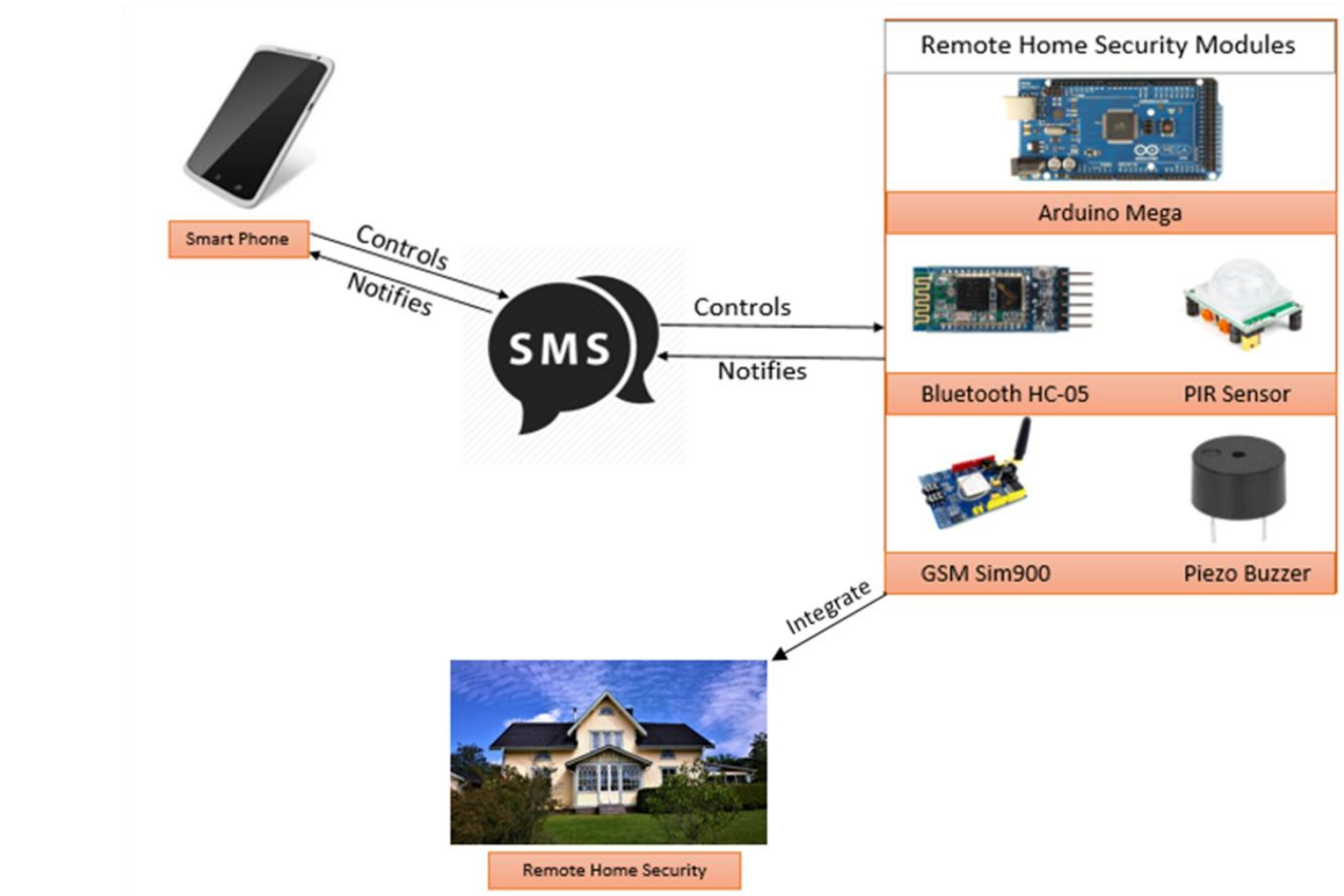

Fig 1: Operational Framework for the Proposed Project
To develop remote home security system using open-source electronic platform with Arduino board, Bluetooth module, GSM module, PIR sensor and piezo buzzer is needed. Arduino board is the main controller used in this project. It detects the signals from PIR sensor and sends commands to GSM module accordingly. The piezo buzzer is an alarm that uses and connects to PIR sensor, this buzzer will work manually and automatically, the Bluetooth module is used to control the smart phone to turn off and turn on the alarm.

\section{PRESENTATION AND ANALYSIS OF DATA}

\subsection{Description of the Project}

The project seeks to implement a remote home security using open-source electronic platform for houses and different establishments. This study looked on different problems encountered by house owners with regards to security such as targeted by the intruders/burglars because of the low-level security. To prevent crimes that were illustrated by the proponents at the proposed project that would include the alarm and motion detects. The siren alarm may be set on when an intruder/theft enters the house where motion is detected. The homeowners will receive a message from the system to let the owners know that an intruder is entered their property.

\subsection{Developmental Platform}

The requirements describe how the user wants the software/hardware should function. Thus well-defined requirements are critical to the success of the project.

The proponents search and explored the situation about the security, analyzed the kind of security and asked if they encountered crimes. Analyzed the materials used to support the remote home security system using open-source electronic platform, this material include PIR sensor, piezo buzzer, GSM module, and Bluetooth module. The proponents have two ways to control the home security system the Mobile Application using Bluetooth this module was used to manually control the system inside the house or at the accurate range of the Bluetooth and the GSM module by sending a message that can notify the owner that there is an unauthorized person inside their property in this set up of the project it's easy to monitor the house because of the fast notification that user can receive and also the user can control the buzzer by sending ON/OFF at the phone number of the GSM module.

\subsection{System Design}

Upon analyzing the area of the house, the proponents proposed to use a mobile application and SMS to monitor the system, this system would be partially installed to the house prototype that proponents made. The remote home security system is designed to prevent crimes like thief, murder or even kidnaping, this home security system has a sensor that is connected to the Arduino mega which is the heart and brain of system, a buzzer that can alarm automatically when the sensor detects a motion and it can be alarmed manually using Bluetooth module, this module can control the system manually it can activate or deactivate the light and alarm, or manually on/off the alarm using connected mobile application. 
The proponents also combined the GSM Sim900 shield to Arduino mega this shield would serve as a messenger of the security, if the sensor is activated and detects a motion it automatically sends a message saying that there is unauthorized person in your house. Since Bluetooth module has a maximum range of 100 meters the proponents decided to add a sending function of a GSM module where the user can manually turn on/off the buzzer and light by sending a correct message. This GSM module can be used even the user is far, by sending the appropriate message the user can control the alarm of the house.

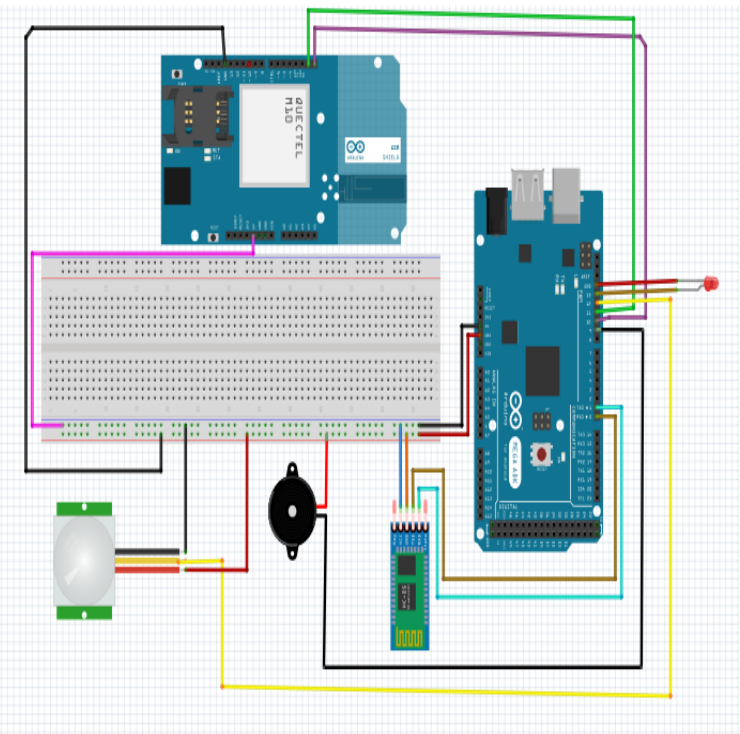

Fig 2: System Design of Remote Home Security Using Open-Source Electronic Platform

Figure 2 show the layout of the remote home security system using open-source electronic platform, this wireframe contains wirings of the project. This modules are PIR sensor, piezo buzzer, Bluetooth module, and GSM module with the Arduino mega board. This modules would function using arduino mega, all of this module is connected to Arduino mega. The proponents decided to add a sending function of GSM module for remote home security this GSM module can control the light and buzzer of the house where the only thing to do is send an appropriate message given by the proponents. The difference between controlling using SMS and mobile application is that the mobile application is connected to a Bluetooth module which is only connected when the user is inside their house or has a limit of 100 meters in a distance and the user can access the system if the user have an mobile application while the controlling using SMS is created by the proponents can monitor and controlled in any location but the user need to know the phone number of the GSM module. Proponents create this controlling using SMS is to add a connection in remote home security so that even the user is outside the town or their house still the user can access their system.

\subsection{Snapshot / Wireframe}

Wireframe is an image or set of images which displays the functional elements of a mobile application, typically used for planning a site's structure and functionality. A wireframe is commonly used to layout content and functionality on a page which takes into user needs and user journeys. Wireframes are used early in the development process to establish the basic structure of a page before visual design and content is added.

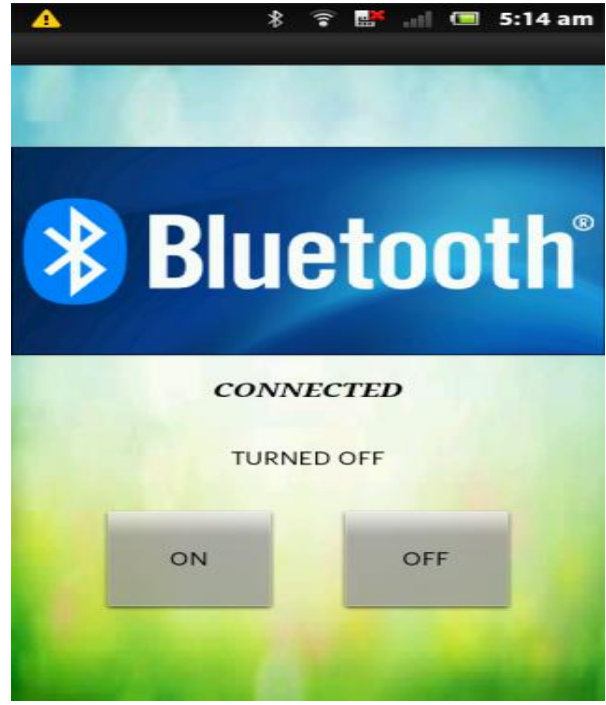

Fig 3: Controller for the System

Figure 3 shows the actual mobile application for the system, this mobile app can manually turn ON/OFF the siren and lights of the house if it is connected to the system.

\subsection{Prototype}

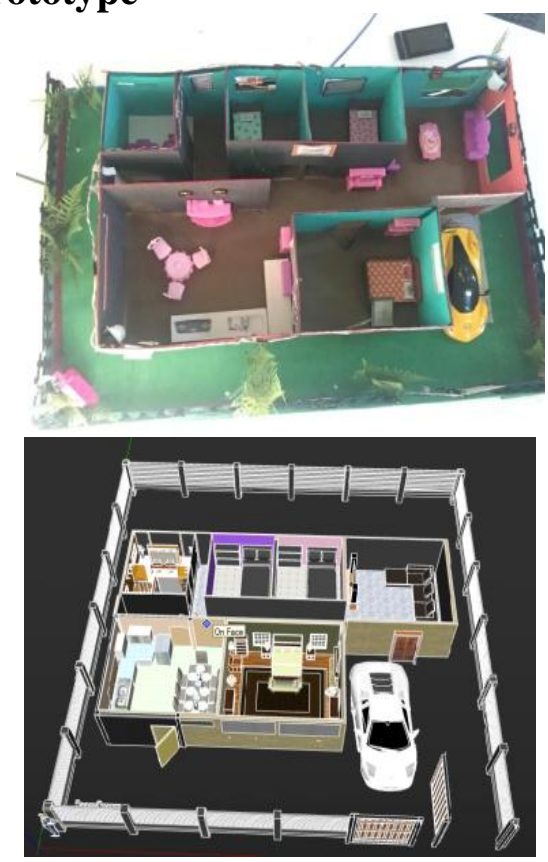

Fig 4: Model Design of Actual House and Digital Design Prototype

Figure 4 is a model of an actual and digital design house prototype that proponents designed, this prototype would serve as a guide of the proponents to make it as an actual house prototype. The places that has a sensor are the possible places that burglars can enter, this places are living room, kitchen and gate/yard. If there is an unauthorized person who enters the gate, the system is activated the lights at the yard will automatically turn on and it will notify the user that there is a person at the yard/gate. If the burglars entered the house like at the living room or kitchen the lights would turn on, the buzzer would alarm and the user would be notified that there is a burglar inside the house. To turn off the buzzer and lights the user can use the first option through Bluetooth device wherein the user need to pair their device to the system. And 
the second option is the user can simply send a message like ON, OFF or STATE.

\subsection{System Testing}

Testing is too important to ensure customer's satisfactions, and it requires no knowledge in coding, hardware configuration. It can also be automated to ensure that the actual outcome are compared and equal to desire outcome. To make sure that code meets its design and requirements as expected, the proponents make a system test and hardware test were functionality through automated testing. The mobile application was installed to an android phone that runs android SDK 26 0reo, and the Arduino and different modules was installed to the house prototype. In this phase the proposed project would understand and developed the product life cycle where to focus on investigation and encounter. During the testing phase the proponents would find out whether their code and programming work according to the clients/stakeholders requirements. While it's not possible to solve all the failures you might find during the testing phase, it is possible to use the results from this phase to reduce the errors within the proposed project.

\subsection{Definition of result}

\section{Tables.4 Survey Result}

\begin{tabular}{|c|c|c|}
\hline Questions & YES & NO \\
\hline - Functionality & & \\
\hline 1. Does the PIR sensor detects a motion human or animal? & 10 & 0 \\
\hline 2. Does the piezo buzzer alarm when the PIR sensor detects a motion? & 10 & 0 \\
\hline 3. Does the system notify the user using SMS or call? & 10 & 0 \\
\hline 4. Can the user manually turn the light and buzzer on/off using SMS? & 10 & 0 \\
\hline $\begin{array}{l}\text { 5. Can the user monitor the status of the buzzer and light by sending a SMS } \\
\text { command? }\end{array}$ & 10 & 0 \\
\hline - Usability & & \\
\hline $\begin{array}{l}\text { 6. After presenting the proposed project, do you feel comfortable when you } \\
\text { leave your house? }\end{array}$ & 9 & 1 \\
\hline
\end{tabular}

The house owner, care taker and family members answered the 10 survey questionnaire. With the total of 10 respondent. 9 answered all questions with a "yes" and 1 respondent answered "no" to the question, "After presenting the proposed project, do you feel comfortable when you leave your house?" According to the survey form completed by the house owners, the prototype and information presented in the mobile application and SMS are problem based environment. Overall, the home security system received a high percentage of "yes" in the survey conducted. Across all 6 questions an average of $90 \%$ of the answers is "yes". While $10 \%$ answered "no".

\section{CONCLUSION AND RECOMMENDATION}

\subsection{Conclusion}

The stakeholders a lack security against burglars and are discomfort in leaving the house. These problems often lead to loss of material things, properties and even loss of lives. As result of the evaluation out of 10 resident who answer the questioner $90 \%$ have a positive outcome and $10 \%$ as not. In this result of the evaluation the proponents have developed the system efficiently and effectively.

\subsection{Recommendations}

As recommended to the homeowners, that want to install the remote home security system they must use a high quality IT equipment to avoid untoward circumstance. Add some CCTV's that can connect to their mobile phones to insure the security and to watch over their house.

\section{REFERENCES}

[1.] Anandan, R., Karthik, B., Kumar, K., 2013 “ Wireless Home and Industrial Automation Security System using GSM"

Website:

https://pdfs.semanticscholar.org/d4ce/41aac1c890e56cf0 7759e7bdee3a42652fb9.pdf

[2.] Halvorse, H. (2017) "Introduction to Arduino an opensource prototyping platform" Brown, L. D., Hua, H., and GAO, C. 2003. A widget framework for augmented interaction in SCAPE.

[3.] Abioye, A., Ajah, G., David, N. (2013) "Web Based Security System Sch. J. Eng. Tech" Website:https://www.researchgate.net/publication/25735 2145_Scholars_Journal_of_Engineering_and_Technolog y_SJET_Web_Based_Security_System

[4.] ABS-CBN News, (2018) "Mga akyat-bahay, 'suki' na sa subdivision sa Kawit" Website:http://news.abscbn.com/news/02/08/18/mga-akyat-bahay-suki-na-sasubdivision-sa-kawit

[5.] ABS-CBN News, (2018) "Pagnanakaw sa 3 establisimyento sa Sampaloc" Website:http://news.abscbn.com/news/02/22/18/sapul-sa-cctv-pagnanakaw-sa-3establisimyento-sa-sampaloc

[6.] ABS-CBN News, (2018) "Lalaki, 'naghakot' ng P2 milyong halaga ng gamit sa condo, pinaghahanap" Website:http://news.abs-cbn.com/news/04/02/18/lalakinaghakot-ng-p2-milyong-halaga-ng-gamit-sa-condopinaghahanap

[7.] Viraj Mali, Ankit Gorasia, Meghana Patil, Prof. P.S.Wawage 2016 "Home Automation and Security using ArduinoMicrocontroller". Website:http://www.ijrat.org/downloads/ncpci2016/ncpci $-45 . \mathrm{pdf}$

[8.] DEVCONHOMESECURITY, 2016 "A Thorough Introduction Of Home Security System" Website: http://devconhomesecurity.com/blog/a-thoroughintroduction-of-home-security-system

[9.] M. Sathishkumar, S.Rajini 2015 "Smart Surveillance System Using PIR Sensor Network and GSM" Website:http://ijarcet.org/wp-content/uploads/IJARCETVOL-4-ISSUE-1-70-74.pdf 